\title{
Capacited P-hub location problem allowing direct flow between spokes in intermodal transportation network
}

\author{
DANIŞMENT VURAL ${ }^{1, * 0}$ and SINAN AYGÜN ${ }^{2}$ \\ ${ }^{1}$ Turkish Land Forces, Ankara, Turkey \\ ${ }^{2}$ Turkish Military Academy, Ankara, Turkey \\ e-mail: danismentvural@gmail.com; sinanaygun2005@yahoo.com.tr
}

MS received 19 October 2018; revised 1 July 2019; accepted 24 July 2019

\begin{abstract}
For the last twenty five years, hub location problems have become an important research area in the Location Theory. The use of hub and spoke network structure in modern transportation and telecommunication systems has a great effect on this. In hub and spoke systems flows from sources are collected in the hubs, which are generally located centrally and serve as collection and distribution points, and distributed to the destinations again via hubs to use advantages of the economies of scale. In this study, real-life problem of a Turkish public institution is addressed. Different from the studies in the literature, we consider an intermodal transportation network where spoke-to-hub and hub-to-spoke transportation could be either land or air movement while hub-tohub transportation is only air movement. The proposed study differs in some respects from studies in the literature. Firstly, obligation to use of hubs for the flows between origin and destination pairs is relaxed. Secondly, due to the special nature of the problem being addressed not all the nodes are considered to be candidates as hubs, instead some specific nodes are taken into consideration. Lastly, hubs' capacities are made to be affected by the flow not only from hubs but also spokes. The results showed that the proposed model produced a lower total cost compared to the studies in the literature and the current applied method.
\end{abstract}

Keywords. Hub and spoke; intermodal transportation; facility location; mathematical modelling.

\section{Introduction}

Hub is a special facility which serves as a collection, classification and transfer point in the many-to-many transportation distribution systems. In hub and spoke problems, flows between source and destination nodes are carried out not directly between each other but through hubs in order to benefit from economies of scale. Flows from different sources to destinations are subjected to consolidate in hubs. These consolidation couplings could be directly between two hubs, as well as from the source node to the hub or from the hub to the destination node [1].

At the heart of hub location problem is a network structure consisting of $n$ nodes defined by source, destination and potential hub points. Hubs serve as collection and distribution points for flows between source-destination pairs. A hub directs many separate small flows into larger ones or combines them. Basic parameters of the problem are; the flow between each source-destination pair, unit transportation cost (cost, time, distance, etc.) and the cost reduction factor $(\alpha)$ used to take advantage of the economies of scale in transportation between hubs.

*For correspondence

Published online: 05 September 2019
In hub location problems, triangular inequality has an important place, therefore, whether the inputs such as distance and cost in the designed problem provide triangular inequality directly and significantly affect the solution of the problem and the calculation of the correct costs of the model. The vast majority of the studies in the literature are based on the assumption that inputs such as distance and cost in the problem conform to the rule of triangular inequality. This assumption facilitates the modeling process. In cases where there is no triangular inequality, it is necessary to add constraints to the designed model, to calculate the correct costs and ensure that streams can travel up to two hubs, one of the basic assumptions of hub location problems.

In general terms, hub location problems, which usually address selecting the hubs and allocating non-hub nodes to these hubs, are location allocation problems. In figure 1, a collection-distribution process is shown for a general hub location problem. In figure 1 it is shown that, the flows going from node $i$ to node $j$ are collected in the hub $k$ together with the flows going from other nodes to node $j$, then transferred to hub $l$ and finally distributed to node $j$ from hub $l$.

Studies on the hub location problem are generally based on three assumptions [1]: 


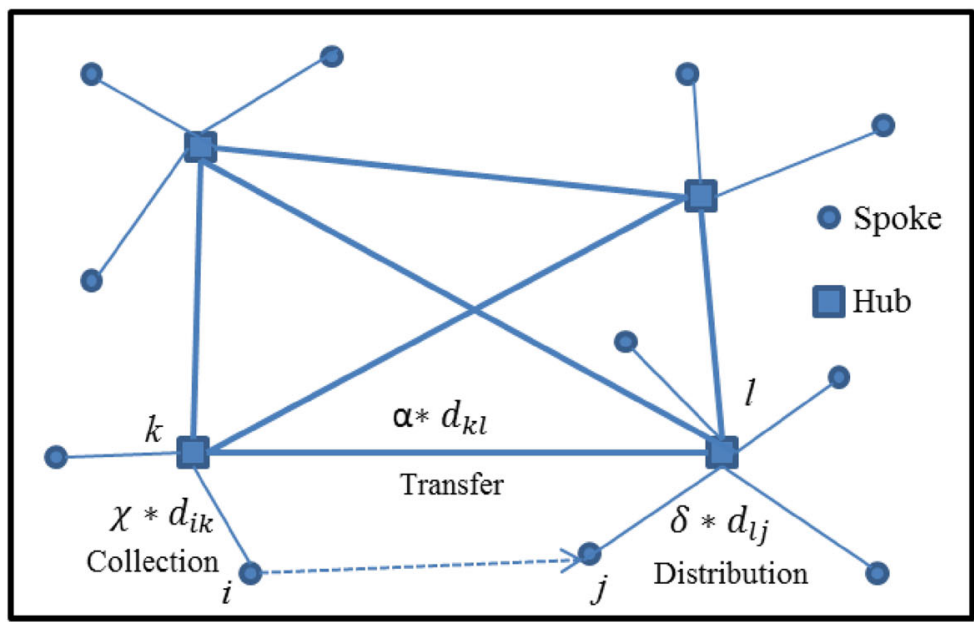

$\chi$ : cost reduction factor for the flow from node $i$ to hub $k$.

$d_{i k}$ : distance between node $i$ and node $k$.

$\alpha:$ cost reduction factor for the flow between hubs.

$\delta:$ cost reduction factor for the flow from hub $l$ to node $j$.

Figure 1. Hub location problem with collection-distribution process.

- Having link between each hub pair, the hub network structure is a complete graph.

- Economies of scale is exploited by using the cost reduction factor $(\alpha)$ for the links between hubs.

- Direct connection between non-hub nodes is not allowed.

In this study, real-life hub location problem of a Turkish public institution is addressed. Based on the demands of the institution and the characteristics of the problem, some dimensions have been added to the capacity constrained and multiple allocation hub location models in the literature. Unlike the studies in the literature, we consider an intermodal transportation network where spoke-to-hub and hub-to-spoke transportation could be either land or air movement while hub-to-hub transportation is only air movement. In the network, not all the nodes are considered to be candidates as hubs, instead some specific nodes (cities with airports) are taken into consideration. Another issue that is suggested to be different from the traditional hub location problems is that obligation to use of hubs for the flows between origin-destination pairs is relaxed thus spoke-to-spoke flow is allowed for some of the nodes under given conditions. In conventional hub location problems, the inter-node flows are provided by at least one transfer point. In this study, this assumption is loosened with the idea that lower cost is obtained due to problem-specific conditions. There is no restriction on hub use if inter-node shipping will reduce total cost. The problem is different from the traditional central location problems in this aspect. Another difference of this study from the studies in the literature is that capacities of the hubs are made affected not only by flows from hubs but also flows from spokes in the network. Proposed mathematical model is constructed in the form of: $p$-hub location problem with multiple allocations, capacity constrained, allowing direct flows between spokes, not having triangular inequalities in the distances among the nodes.

A literature survey on hub location problems is given in the next section of the study. In the third section, the problem to be studied is explained in detail and developed mathematical model for the solution of the problem is presented. In the last section, the obtained results are evaluated and suggestions are given for future studies.

\section{Literature review}

Hub location problem was first proposed by O'Kelly [2]. In this work, O'Kelly has developed basic models with one and two hubs and noted that the number of direct assignments for each source-destination pair will decrease if flows are sent over hubs. The first mathematical model for the hub location problem was developed by O'kelly [3] with a study of the air transportation network. Considering the first studies on hub location problems, the mathematical model with the quadratic objective function developed by O'Kelly has a critical role [4]. Campbell $[5,6]$ then proposed several mathematical models with similar objective functions related to hub location problems. In addition, Aykin [7-10] with flow-based assignment approach and Klincewicz $[11,12]$ with both flow and distance-based assignment procedures have played a critical role in the expansion of the field. The first mathematical model for capacity constrained, multiple allocation hub location problems, which is the subject of this study, was developed by Campbell [6]. Then, constructing capacity constrained, multiple allocation hub location problem for the mail distribution network, Ebery et al. [13] have proposed two different models and noted that the capacity of the hubs to be selected was affected by only collection phase of the mail distribution. 
Sasaki and Fukushima [14] have proposed a model for capacitated multi assignment hub location problems. In this model, capacity limits are applied for both hubs and spokes. Boland et al. [15] summarized some of the features of optimal solutions of the capacitated and uncapacitated multiple allocation hub location problems. Examining the results of the optimal solutions, the authors developed preprocessing procedures and tightening constraints to apply linear programming relaxation to the existing mixed integer linear programming models. Based on the same idea as the model developed by Ebery et al. [13], Marin [16] has proposed a new model for multiple allocation capacitated hub location problems that does not allow direct flow between two non-hub nodes.

Rodriguez et al. [17] proposed a new model in which each hub is considered as capacitated and modeled with the $M / M / 1$ queuing system. The developed model is solved by simulated annealing algorithm. Rodriguez and Salazar [18], considering the hubs and the flows between nodes as capacitated, proposed a new mixed integer model for an incomplete network. The proposed model was solved by two separate branch and bound based decomposition techniques.

Gelareh and Pisinger [19] proposed a mixed integer model for a sea service provider distribution. Based on a 4-index formulation of the hub location problem in a network, the authors get the optimal solution by employing a primal decomposition method. Sender and Clausen [20] have proposed a mathematical model for the multiple allocation capacitated German freight transportation problem. Using a special data set, the researchers solved the problem by CPLEX solver and the developed local healingbased heuristic. Shahabi and Unnikrishnan [21] proposed a mixed integer nonlinear mathematical model for the single and multiple allocation hub location problems, whose demands and distributions are unclear.

Karimi and Cetak [22] proposed a mathematical model for the multiple allocation hub location problem in an incomplete graph network and reached the best solutions by specifying that their model can be used in other hub location problems with a few additional other constraints. Fang et al. [23] considered flow-dependent set-up cost in multiple allocation hub location problem. In their study, set-up cost is assumed to be proportional to the total amount of flows through the hub. In order to minimize transportation and set-up costs, an integer linear programming model is developed. The incremental optimization of hub and spoke network problem is considered in the paper of Wang and Huang [24]. Considering the change in the number of spokes and the flow as the time goes by, proposed model aims to cope with the change. Two mixedinteger linear programming formulations are proposed and analyzed for this problem while the objective is to minimize the total cost, which includes the set-up costs for the new hubs, the closure and the adjustment costs for the original hubs and the routing costs.

Serper and Alamur [25] used alternative transportation modes and different types of vehicles in the hubs. In addition to the locations and capacities of hubs, transportation modes and the number of vehicles belonging to these modes to serve at hubs, allocation of non-hub nodes to hubs and routing the demand between origin-destination pairs are determined in the study. A mixed-integer programming model is developed and a variable neighborhood search algorithm is proposed for the solution of the problem, which is minimizing the total cost including hub set-up cost, procurement and operational costs of vehicles, transportation costs and material handling costs. Mokhtar et al. [26] considered the real-world logistics problems in an intermodal network and extended the traditional hub location problem by incorporating three transfer modes and two kinds of hubs. They do not assume that the underlying network is fully connected or that hubs and access nodes are directly connected in the study. Kartal et al. [27] aimed to find the hub location and routing in a network which allows simultaneous pick-up and delivery by vehicles. They suggested three alternative mixed integer programming formulations and a heuristic of multi-start simulated annealing and ant colony system.

Karimi et al. [28] propose a multimodal hub location problem in which commodities are split by capacited hubs and transportation systems. A Mixed Integer Linear Programming (MILP) model is formulated in a multi-commodity network where the demands are stochastic. The problem decides on the optimum location of hubs and allocation of spokes to established hubs with the aim of cost minimization. Mohammadi et al. [29] consider the singleallocation p-hub location problems and the effect of uncertainties (i.e., natural disasters or terrorist attacks) on deliveries in France transportation network. Proposing an approximation approach to provide a lower bound for the optimal Pareto-frontier, a hybrid meta-heuristic algorithm is used to solve bi-objective capacitated p-hub location model to near optimality.

Considering operational and disruption risks, Zhalechian et al. [30] propose a new framework to design a hub network. The proposed framework takes into consideration risks by considering three resilience dimensions (proactive/ reactive capability and design quality). A hybrid solution approach is proposed to solve the problem in which a new objective function is introduced to assess the designed hub network's resilience level. Hu et al. [31] propose a multiple assignment model for the joint design of the fleet size and the number, locations and capacities of hubs for the thirdparty logistics systems. Consolidating hubs as a hub-andspoke network, a math-heuristic algorithm is proposed to solve the problem, which is decomposed into two subproblems. The objective is formulated as to minimize the total costs, including congestion costs, which is formulated by the route travel time as an increasing function of the number of trucks on the route.

When the studies in the literature are searched, it is seen that the studies done up to now are insufficient to meet the basic characteristics of the problem considered in this 
study. Unlike the others in the literature, in this study, the necessity of using hub for flows between source-destination pairs is relaxed and the capacities of the nodes selected as hub are affected by flows from nodes that are both selected and not selected as hub.

Aygun et al. [32] studied same problem of this study. The difference between these two studies is that while Aygun et al. [32] have tried to determine optimal number of the hubs by mathematical model, in this study the number of the hubs is constrained by the decision makers. The number of hubs to be opened within the scope of the study is a strategic decision. The number of hubs also affects many other factors, such as ease of operation, the amount of personnel required to operate the hubs, the number of temporary accommodations and security. For this reason, the number of hubs to be opened in the research is left to the decision-makers' initiative.

\section{Application}

In this study, the real-life problem of a public institution in Turkey is addressed. The public institution must periodically send some of its employees safely between western and eastern cities of the "Erzincan-Elazığ-DiyarbakırMardin" line and among the eastern cities of the line. In the problem, employees can be transported both by land and air. Because of the security reasons, the cost of transportation by land between some nodes is very high. Transportation on the western part of the line is the employees' own responsibilities and excluded from this study.

In the current operating system, employees can only travel using the road or airway, or both the road and airway together, according to the routes determined by the institution. There are 12 airports on the west side of the line designated for airway transportation and 9 airports in the east. The personnel who use the airway can not use an airport other than the nearest one.

Personal transportation in the current system to be explained with an example; an employee who is travelling to Ardahan from Tunceli (which both cities are in the eastern part) is first transported to the nearest airport Elazig by road, then fly to the Istanbul airport (used as a hub in the current system), then fly to Kars airport from Istanbul airport and finally transferred to Ardahan by road. Due to the fact that there is no agreement with airline companies at present, they are adhering to scheduled flights for air transportation which leads to unnecessary flight costs and waste of time. When travel times and transfer times are included, travel from Tunceli to Ardahan can be done for 1 week. Tunceli-Ardahan transfer described in the example and airports in Turkey are shown in figure 2. The red arrows in figure 2 show travels by road and the blue arrows show travel by air.

In the course of designing the problem, firstly, the requests of the management of the institution have been determined. These requests are listed as follows:

- All employees are required to be transported by air as much as possible,

- Transportation to Erzincan, Elazı $\breve{g}$, Diyarbakır and Mardin from western cities by land can be possible (cities in the line),

- Transportation by land to the eastern neighbor cities of "Erzincan, Elazı ̆̆, Diyarbakır, Mardin" line from western cities can also be possible (if allowed by the agency),

- Transportation by land among some cities in the eastern part of the line is possible only if allowed by the agency,

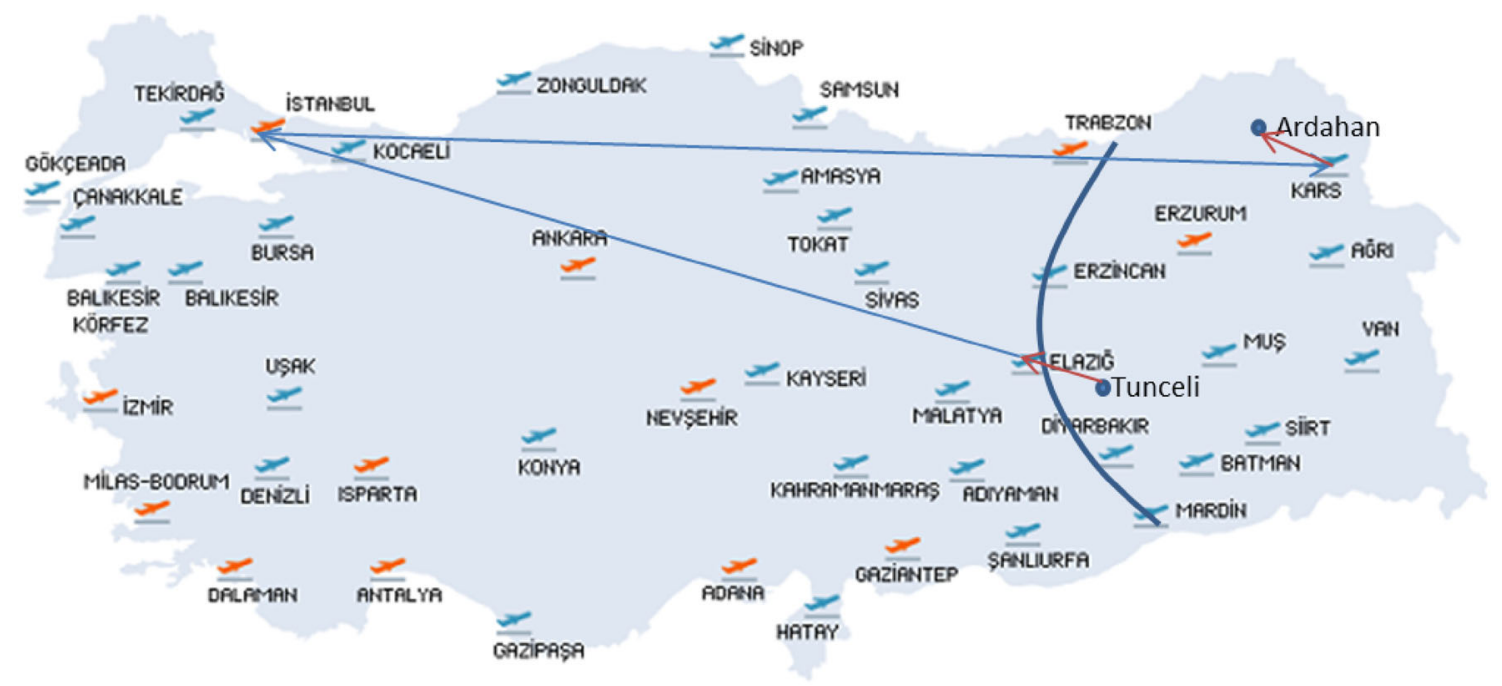

Figure 2. Airports in Turkey. 
- In order to gain cost advantage, instead of being sent individually by scheduled flights, employees should be transported by rented airplanes by using the designated airports.

In order to develop a mathematical model in accordance with the structure of the problem, the model developed by Marin [16] is based on and new dimensions are added to the model. Considering the postal distribution network problem, Marin proposed a mathematical model for the capacitated multiple allocation hub location problems in a network where triangular inequalities can not be provided between the nodes. In the study, based on the thought that the mail was classified when it reached hubs and no further action was taken, he suggested that the hubs' capacities were influenced only by flows from non-hub nodes.

Considering the structure of the problem dealt with in this study; the necessity of using hub in flows between source-destination pairs is relaxed, and a new model has been developed that permits direct traversal without using hub unlike the model of Marin [16]. Besides, different from the capacity constraint in the model developed by Marin [16], the capacities of the hubs are determined by the flows from the nodes which are both selected and not selected as hubs. In the model proposed by Marin [16], the number of hubs to be located is determined by the mathematical model, while the number of hubs to be located is determined by the decision maker in this study.

\subsection{Assumptions}

The mathematical model has been developed based on the following assumptions that are approved by the institution:

- Transportation from spoke to hub in the west will be carried out individually by road.

- Transportation between hubs will be done collectively by air.

- Transportation from hub to eastern spoke will be done collectively by road.

- All spoke-to-spoke transportation (in only allowed routes) will be done individually by road.

- The institution transports its employees four terms in a year. In this study one term is considered.

- The flows used in the mathematical model are assumed to be deterministic and to be performed at the same term.

The mathematical model and the variable/parameter definitions in the model are presented in the following sections.

\subsection{Parameters}

In the problem, there is a single network $(N)$ covering all "81" cities in Turkey. Therefore, all indices are contained within the same network and selected from the same network. Cities are expressed by cities' plate codes in the network. In hub location problems all nodes are candidate hubs but in this study, all " 81 " nodes are not candidates for being hub. Since the institution wants its personnel to be transported by air as much as possible, among the nodes, " 42 " of them with airports are designated as candidate hubs, where the contracted airline can use. The explanations for the parameters in the mathematical model are presented below.

$W_{i j}$ : The amount of flow from source node $i$ to destination node $j(i=1, \ldots, 81 ; j=1, \ldots, 81)$

$r_{i j}$ : Road distance between source node $i$ and destination node $j(i=1, \ldots, 81 ; j=1, \ldots, 81)$

$h_{i j}$ : Air distance between source node $i$ and destination node $j(i=1, \ldots, 81 ; j=1, \ldots, 81)$

$\Gamma_{k}$ : The capacity of node $k(k=1, \ldots, 81)$

$p$ : Number of hubs to be located which is determined by the decision maker

$\alpha$ : Cost reduction factor for the transfer (from hub to hub). In hub location problems, a constant $\alpha$ valued between 0 and 1 is used to benefit from the scale economy of flows between hubs [33,34]. In this study, air transports between the hubs are carried out by the leased aircraft instead of individual flights. The 0.6 reduction factor reflects the difference between the cost of airplane leasing and individual flight costs. As the value of the cost reduction factor decreases, the hub utilization rate will increase for shipments from one node to another node. As this value increases, the number of direct shipments between nodes will increase as the advantage of using hubs will be eliminated.

$\delta$ : Cost reduction coefficient for distribution (from hub to non-hub destination node). The cost reduction coefficient $\delta$ arises from the ability of the institution to use its own vehicles for distribution to the spokes from the hubs. The coefficient is determined as $\delta=0.8$. This number reflects the cost difference between the cost of individual transport and the cost of public transport. The scale economics of transportation in bulk is taken into account while the coefficient is being determined. The decrease in the $\delta$ value, as in the $\alpha$ parameter, will increase the use of the hub.

In determining both $\alpha$ and $\delta$, average cost prices are gathered from Turkish Statistical Institute [35].

$\mho$ : land transportation cost coefficient for $1 \mathrm{~km}$ (\$0.09),

$\phi$ : air transportation cost coefficient for $1 \mathrm{~km}(\$ 0.13)$,

Distances between nodes $\left(r_{i j}\right.$ and $\left.h_{i j}\right)$ were taken from the General Directorate of Highways web page [36]. The distance matrices are arranged in two different ways for the road and airway transportation. Large penalty coefficients are given into the relevant cell of the road distances matrix for distances between nodes that are not allowed to go directly by the institution, so that transportation between these nodes are prevented. Large penalty coefficients are also given into the relevant cell of the airway 
distances matrix for distances between nodes that do not have airports, so that transportation between these nodes are prevented as well. The road transportation costs $\left(R_{i j}\right)$ and airway transportation costs $\left(H_{i j}\right)$ are obtained by calculating the related elements of the distance matrices $\left(r_{i j}\right.$ or $h_{i j}$ ) and one-kilometer road transportation cost coefficient (ひ) or one-kilometer airway transportation cost coefficient $(\phi)$.

The triangle inequalities between nodes are not satisfied due to the penalties entered into the related cells of the distance matrices. In cases where triangular inequality can not be satisfied, it is necessary to add additional constraints to the model in order to calculate the costs correctly and make the flows travel up to two hubs which is one of the basic assumptions of hub location problems. In this study, the constraints developed by Marin [16] were used to ensure that the flow from source to destination point using up to two nodes.

In fixed cost hub location problems, nodes, which are selected as hub, have a fixed installation cost. This study is designed as a fixed cost, capacity constrained hub location problem. However, the instituion has operating facilities already installed at all cities which have airports. Therefore, if the city with airport is selected as hub, the cost of reestablishment will be incurred. If an existing facility is not selected as a hub, it is considered that the facility will continue to be used for another purpose by the institution and that the facility shutdown cost will not be incurred. For this reason, fixed organization cost is excluded from the problem.

\subsection{Decision variables}

$a_{m j}$ : the amount of flow from node $m$ to node $j$, in case $\mathrm{m}$ is a hub and $j$ is not a hub,

$b_{k m j}$ : the amount of flow from node $k$ through $m$ to node $j$, where nodes $k$ and $m$ are hubs and $j$ is not a hub,

$c_{i k j}$ : the amount of flow going from node $i$ to node $j$ using the node $k$, in case node $k$ is a hub and $i$ is not a hub,

$Y_{k}$; a binary variable that takes the value " 1 " in case $k$ is selected as a hub, and " 0 " in other cases,

$e_{i j}$ : the amount of flow going directly from node $i$ to node $j$ without using a hub, where nodes $i$ and $j$ are not hubs,

There are five types of decision variables in the model. The first type of decision variable (a) specifies the amount of flow in the case where the starting point is a hub and the destination is a non-hub node. The second type of decision variable $(b)$ indicates the amount of flow where the starting point and the second node are hubs. The third type of decision variable $(c)$ specifies the amount of flow where the starting point is a non-hub node and the second node is a hub. The fourth type of decision variable $(e)$ indicates the flow directly from the source point to the destination point, without using a hub, in the case where the starting and destination points are non-hub nodes. The fifth type of decision variable $(Y)$ is a binary variable and takes the value " 1 " when a node is selected as a hub, and takes " 0 " when it is not selected. All possible alternative ways how the decision variables are valued are presented in figure 3 .

In alternative path (1), the start node $i$ is a non-hub node, $k$ and $m$ nodes are hubs, and the destination node $j$ is a nonhub node. The flow between $i$ and $k$ nodes is denoted by $c_{i k j}$ decision variable. The $c_{i k j}$ decision variable takes a value when the starting node is a non-hub node and the second node is a hub. The continuation of the same flow, the flow between $k$ and $m$ nodes is expressed by the decision variable $b_{k m j} . b_{k m j}$ takes a value if the first and second nodes are hubs. The flow between nodes $m$ and $j$ at the end of the same path is denoted by $a_{m j}$ decision variable. The decision variable $a_{m j}$ takes a value if the first node is a hub and the second node is a non-hub node.

\subsection{Mathematical model}

Mathematical Model is designed as a capacity constrained (where the capacities of hubs are affected by flows from nodes that are selected as both hub and non-hub), multiple allocation hub location problem that allows direct access between spokes.

Objective Function:

$$
\begin{aligned}
\operatorname{Min} & \sum_{i} \sum_{k} \sum_{j} R_{i k} c_{i k j}+\sum_{k} \sum_{m} \sum_{j} \alpha H_{k m} b_{k m j} \\
& +\sum_{m} \sum_{j} \delta R_{m j} a_{m j}+\sum_{i} \sum_{j} R_{i j} e_{i j}
\end{aligned}
$$

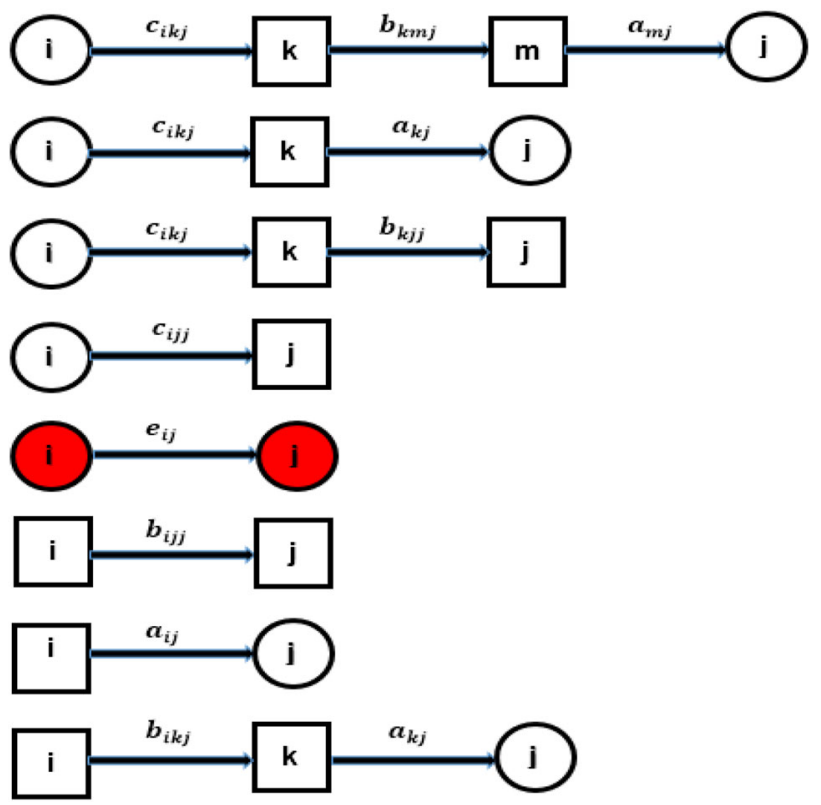

Figure 3. Possible routes in the problem and the tasks of the decision variables. 
Constraints:

$$
\begin{aligned}
& \sum_{m} a_{m j}+\sum_{m} b_{m j j}+\sum_{m} c_{m i j}+\sum_{m} e_{m j}=\sum_{i} W_{i j} \quad \forall j \\
& e_{i j}+a_{i j}+\sum_{k} b_{i k j}+\sum_{k} c_{i k j}=W_{i j}+\sum_{k} b_{k i j}+\sum_{k} c_{k i j} \\
& \forall i, \forall j \neq i,
\end{aligned}
$$

$$
\sum_{k} b_{k m j}+\sum_{k} c_{k m j} \leq\left(\sum_{i} W_{i j}-W_{m j}\right) Y_{m} \quad \forall j, \forall m \neq j
$$

$$
\begin{gathered}
\sum_{k} b_{k j j}+\sum_{k} c_{k j j}=\sum_{i} W_{i j} Y_{j} \quad \forall j \\
c_{i k j} \leq W_{i j} Y_{k} \quad \forall i, j, k
\end{gathered}
$$$$
e_{i j}+\sum_{k} c_{i k j}=W_{i j}\left(1-Y_{i}\right) \quad \forall i, j,
$$$$
\sum_{m} b_{k m j} \leq W_{k j}+\sum_{i} c_{i k j} \quad \forall k, j,
$$$$
\sum_{i} \sum_{j} c_{i k j}+\sum_{i} \sum_{j} b_{i k j} \leq \Gamma_{k} Y_{k} \quad \forall k,
$$$$
e_{i j} \leq W_{i j}\left(1-Y_{i}\right) \quad \forall i, j,
$$$$
e_{i j} \leq W_{i j}\left(1-Y_{j}\right) \quad \forall i, j,
$$$$
\sum_{k} Y_{k}=p \quad k=1, \ldots, 81
$$$$
b_{j m j}=0 \quad \forall j, \forall m \neq j,
$$$$
b_{k k j}=0 \quad \forall j, \forall k \neq j
$$$$
c_{k k j}=0 \quad \forall j, k,
$$$$
a_{j j}=0 \quad \forall j,
$$$$
Y_{k} \in\{0,1\} \quad \forall k,
$$$$
b_{k m j}, c_{i k j}, a_{m j}, e_{i j} \geq 0 \quad \forall i, j, k, m,
$$

$i=1, \ldots 81 ; j=1, \ldots 81 ; k=1, \ldots 81 ; m=1, \ldots 81$.

The objective function (1) of the model aims to minimize the total cost of transportation for outgoing flows using a hub from one province to the other (up to two) or without hubs. Objective function's first part $\left(\sum_{i} \sum_{k} \sum_{j} R_{i k} c_{i k j}\right)$ expresses the aggregation process (from a non-hub source node to a hub) and the decision variable $c_{i k j}$ is multiplied by the cost of road transportation. Second part of the objective function $\left(\sum_{k} \sum_{m} \sum_{j} \alpha H_{k m} b_{k m j}\right)$ expresses the transfer process (hub to hub) and the decision variable $b_{k m j}$ is multiplied by the airway transportation cost and cost reduction factor $\alpha$. The third part $\left(\sum_{m} \sum_{j} \delta R_{m j} a_{m j}\right)$ expresses the process of distribution (from a hub to a nonhub destination node) and the decision variable $a_{m j}$ is multiplied by the $\delta$ coefficient in addition to the cost of road transportation. The fourth part $\left(\sum_{i} \sum_{j} R_{i j} e_{i j}\right)$ expresses the direct flow among nodes without using a hub and decision variable $e_{i j}$ is multiplied by the cost of road transportation.

The constraint (2) guarantees that the demands of all branches of the instution on each city are met. The constraint implements this process by equalizing all of the flow from node $m$ to node $j$ to all of the flow from node $i$ to $j$ node.

Constraint (3) balances the flows and prevents flow loss. The constraint implements this operation by expressing all possible inbounds and outbound flows of node $i$. On the right hand side of the constraint are all possible inbound flows and on the left side all possible outbound flows of node $i$.

The constraint (4) allows the decision variable $b_{k m j}$, which represents the flow (transfer) between the hubs, to have a value only if $k$ and $m$ nodes are chosen as hubs.

The constraint (5) allows the $b_{k j j}$ decision variable, which represents the flow (transfer) between the hubs, to have a value only if $k$ and $j$ nodes are chosen as hubs.

The constraint (6) allows the $c_{i k j}$ decision variable, which represents the flow (collection) to the hub from the non-hub source node, to have a value only if $k$ node is chosen as hub.

The constraint (7) ensures that the decision variables $c_{i k j}$ and $e_{i j}$ cannot have a value if a source node $i$ is selected as a hub. Through these two constraints, the $c_{i k j}$ decision variable can only have a value if node $i$ is a non-hub node and node $k$ is a hub. Constraint (8) ensures the flow between any source-destination nodes to be completed by visiting maximum two hubs. This constraint prevents visiting more than two hubs due to the triangular inequality between the distances. The constraint performs this by using the upper bound of the sum of the flows from the node $\mathrm{k}$ which is selected as a hub. Thus, when a flow arrives to node $k$, which is selected as a hub, from another hub, then this flow is forced to go directly to node $j$ by $a_{m j}$ distribution (from a hub to a non-hub node) decision variable.

Constraint (9) is the capacity constraint. There is one or more facilities belonging to the institution in " 42 " cities (nodes) which have an airport and these facilities have a certain capacity. The capacities for the candidate-to-be-ahub nodes are calculated by summing the bed capacities of the accommodation facilities on that city (node). This constraint prevents the flow coming from all nodes either selected or not selected as a hub to a node $k$, which is selected as a hub, from exceeding the capacity.

Constraint (10) ensures that $e_{i j}$ decision variable does not take the value when the node $i$ is chosen as a hub, and the constraint number (11) likewise ensures that $e_{i j}$ decision variable does not take the value when the node $j$ is chosen as a hub. In other words, constraints (10) and (11) ensure 
Table 1. Sample routes.

\begin{tabular}{|c|c|c|}
\hline Source & Destination & Route \\
\hline Mersin & Ağrri & Mersin-Adana-Ağri \\
\hline Adiyaman & Bitlis & Adiyaman-Batman-Bitlis \\
\hline Erzurum & Ăgri & Erzurum-A Ăgri \\
\hline Çankiri & Hakkâri & Çankiri-Amasya-Van-Hakkâri \\
\hline Bilecik & Ardahan & Bilecik-Ankara-Kars-Ardahan \\
\hline Antalya & Van & Antalya-Van \\
\hline Tunceli & Ağri & Tunceli-Bingöl-A ğgri \\
\hline Balikesir & Muş & Balikesir-Bursa-Muş \\
\hline Aydin & Bitlis & Aydin-Denizli-Muş-Bitlis \\
\hline Tunceli & Antalya & Tunceli-Elaziğg-Antalya \\
\hline Gaziantep & I ğdir & Gaziantep-Iğdir \\
\hline Kirklareli & Van & Kirklareli-Istanbul-Van \\
\hline Manisa & Hakkâri & Manisa-Izmir-Sirnak-Hakkâri \\
\hline Ardahan & Kars & Ardahan-Kars \\
\hline Sakarya & Bitlis & Sakarya-Kocaeli-Bingöl-Bitlis \\
\hline Isparta & Ĭğdir & Isparta-Konya-I ğdir \\
\hline Kütahya & Ăgri & Kütahya-Ă̆ri \\
\hline Malatya & Ardahan & Malatya-Kars-Ardahan \\
\hline Osmaniye & Erzurum & Osmaniye-Kahramanmaraş-Erzurum \\
\hline Muğla & Hakkâri & Muğla-Sirnak-Hakkâri \\
\hline Bitlis & Ankara & Bitlis-Muş-Ankara \\
\hline Aksaray & Ağri & Aksaray-Nevşehir-Ağri \\
\hline Bitlis & Siirt & Bitlis-Siirt \\
\hline Tunceli & Ankara & Tunceli-Sivas-Ankara \\
\hline Ordu & Hakkâri & Ordu-Trabzon-Van-Hakkâri \\
\hline Hakkâri & Bitlis & Hakkâri-Van-Bitlis \\
\hline Bitlis & Adana & Bitlis-Batman-Adana \\
\hline Hakkâri & Antalya & Hakkâri-Sirnak-Antalya \\
\hline Iğdir & Ankara & Ĭgdir-Ankara \\
\hline
\end{tabular}

that the decision variable $e_{i j}$ can only be valued when nodes $i$ and $j$ are not selected as hub. Constraint (12) allows the decision maker to specify the number of hubs to be opened.

The constraints (13), (14), (15) and (16) are constraints created for the decision variables, which cannot be located in the model, to have value " 0 ".

Constraint (17) allows the decision variable $Y_{k}$ to have a value of " 0 " or " 1 ".

The constraint (18) allows all decision variables in the model to be greater than 0 and have integer values.

\subsection{Results of the mathematical model}

The proposed model is coded in GAMS IDE 2.0.34.19 software and the best solutions are obtained by the CPLEX 10. 1 solver for $p=2,3, \ldots, 42$ values. There are 659,521 integer variables and 7995 constraints in the model. The solutions show that the lowest objective function value is obtained for $p=35$. In the best solution, the objective function value is calculated as $\$ 1,964,973$. Total transportation cost is $\$ 2,755,712$ in the current system. If 35 hubs located, the proposed model provides $40 \%$ cost advantage over the existing system.
Table 2. Allowed direct routes without using hub.

\begin{tabular}{|c|c|c|}
\hline Source & Destination & Route \\
\hline \multirow[t]{3}{*}{ Artvin } & Erzincan & Artvin-Erzincan \\
\hline & Erzurum & Artvin-Erzurum \\
\hline & Ardahan & Artvin-Ardahan \\
\hline \multirow[t]{2}{*}{ Diyarbakir } & Mardin & Diyarbakir-Mardin \\
\hline & Tunceli & Diyarbakir-Tunceli \\
\hline \multirow[t]{2}{*}{ Erzincan } & Erzurum & Erzincan-Erzurum \\
\hline & Tunceli & Erzincan-Tunceli \\
\hline \multirow[t]{4}{*}{ Erzurum } & Erzincan & Erzurum-Erzincan \\
\hline & Mardin & Erzurum-Mardin \\
\hline & Tunceli & Erzurum-Tunceli \\
\hline & Ardahan & Erzurum-Ardahan \\
\hline \multirow[t]{3}{*}{ Giresun } & Erzincan & Giresun-Erzincan \\
\hline & Erzurum & Giresun-Erzurum \\
\hline & Tunceli & Giresun-Tunceli \\
\hline \multirow[t]{3}{*}{ Gümüşhane } & Erzincan & Gümüşhane-Erzincan \\
\hline & Erzurum & Gümüşhane-Erzurum \\
\hline & Tunceli & Gümüşhane-Tunceli \\
\hline \multirow[t]{2}{*}{ Mardin } & Diyarbakir & Mardin-Diyarbakir \\
\hline & Erzurum & Mardin-Erzurum \\
\hline \multirow[t]{3}{*}{ Ordu } & Erzincan & Ordu-Erzincan \\
\hline & Erzurum & Ordu-Erzurum \\
\hline & Tunceli & Ordu-Tunceli \\
\hline \multirow[t]{2}{*}{ Rize } & Diyarbakir & Rize-Diyarbakir \\
\hline & Ardahan & Rize-Ardahan \\
\hline \multirow[t]{3}{*}{ Tunceli } & Diyarbakir & Tunceli-Diyarbakir \\
\hline & Erzincan & Tunceli-Erzincan \\
\hline & Erzurum & Tunceli-Erzurum \\
\hline \multirow[t]{3}{*}{ Bayburt } & Diyarbakir & Bayburt-Diyarbakir \\
\hline & Erzincan & Bayburt-Erzincan \\
\hline & Erzurum & Bayburt-Erzurum \\
\hline Ardahan & Erzincan & Ardahan-Erzincan \\
\hline
\end{tabular}

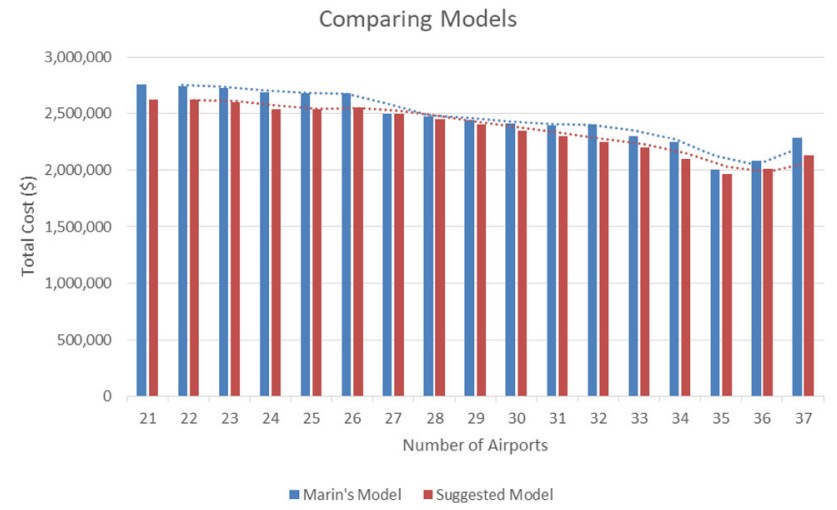

Figure 4. Comparison of two models.

In table 1 , sample routes defined by the model for $p=35$ are presented. In the table, the cities, which are written bold, are the hubs offered by the model. As an example from table 1 for the personnel transportation between Aydin and Bitlis could be described as follows; from Aydin 
Table 3. Total costs (\$) with varying ' $\alpha$ ' and ' $\delta$ ' values.

\begin{tabular}{lccccccccccc}
\hline \multicolumn{10}{c}{$\alpha$} & \multicolumn{10}{c}{$\delta$} \\
\cline { 2 - 12 } & 0 & 0.1 & 0.2 & 0.3 & 0.4 & 0.5 & 0.6 & 0.7 & 0.8 & 0.9 \\
\hline 0 & $1,239,139$ & $1,246,522$ & $1,304,002$ & $1,383,744$ & $1,478,475$ & $1,488,640$ & $1,578,288$ & $1,624,689$ & $1,626,545$ & $1,662,390$ & $1,675,608$ \\
0.1 & $1,277,131$ & $1,284,741$ & $1,281,268$ & $1,409,226$ & $1,523,805$ & $1,498,484$ & $1,626,678$ & $1,674,502$ & $1,687,999$ & $1,713,359$ & $1,726,982$ \\
0.2 & $1,303,055$ & $1,310,819$ & $1,371,264$ & $1,437,831$ & $1,554,736$ & $1,565,426$ & $1,640,721$ & $1,708,493$ & $1,742,931$ & $1,748,138$ & $1,701,597$ \\
0.3 & $1,324,509$ & $1,302,426$ & $1,393,842$ & $1,461,504$ & $1,580,334$ & $1,591,200$ & $1,687,024$ & $1,736,622$ & $1,831,355$ & $1,776,921$ & $1,791,049$ \\
0.4 & $1,336,100$ & $1,344,062$ & $1,406,040$ & $1,474,295$ & $1,523,058$ & $1,605,125$ & $1,701,788$ & $1,751,820$ & $1,786,160$ & $1,792,471$ & $1,806,723$ \\
0.5 & $1,403,920$ & $1,412,286$ & $1,477,410$ & $1,549,129$ & $1,675,083$ & $1,686,600$ & $1,826,123$ & $1,860,276$ & $1,831,355$ & $1,883,456$ & $1,898,431$ \\
0.6 & $1,489,887$ & $1,498,765$ & $1,567,876$ & $1,643,987$ & $1,777,654$ & $1,789,876$ & $1,897,665$ & $1,953,456$ & $1,964,973$ & $1,998,786$ & $2,014,678$ \\
0.7 & $1,569,148$ & $1,578,499$ & $1,651,287$ & $1,731,447$ & $1,872,225$ & $1,885,097$ & $1,998,621$ & $2,057,380$ & $2,012,345$ & $2,105,121$ & $2,121,859$ \\
0.8 & $1,652,284$ & $1,633,653$ & $1,738,774$ & $1,823,182$ & $1,971,418$ & $1,984,972$ & $2,104,510$ & $2,166,383$ & $2,099,976$ & $2,216,654$ & $2,274,571$ \\
0.9 & $1,777,733$ & $1,788,326$ & $1,870,790$ & $1,961,605$ & $2,085,544$ & $2,099,883$ & $2,264,294$ & $2,330,864$ & $2,178,987$ & $2,384,951$ & $2,403,914$ \\
1 & $1,830,624$ & $1,841,532$ & $1,895,092$ & $2,019,967$ & $2,184,203$ & $2,199,221$ & $2,388,591$ & $2,400,211$ & $2,234,667$ & $2,455,908$ & $2,475,435$ \\
\hline
\end{tabular}

to Denizli, which is selected as a hub, individually by land, from Denizli to another hub Muş collectively by air and from Muş to Bitlis collectively by land.

As opposed to the existing system, the obtained solutions show that for a given source city, assigned airport could change according to destinations. For example; Employees in Tunceli go to Ağrı using Bingöl airport, to Antalya using Elazığ and to Ankara using Sivas airports in the proposed system. The results show that obligation in using the same airport for all the flow from the same source point to the different destination points should be lifted and load couplings must be done in the right hubs.

One of the basic assumptions of traditional hub location problems is that flows must use hubs. In the best solution obtained by relaxing this constraint; it is shown in table 2 that which source-destination couples should be transported individually by land. These routes are assessed as safe routes by the institution. The other routes assessed as dangerous are prevented by mathematical model using big penalties.

The institute uses " 21 " airports in the current system. When compared with the solution obtained by $p=21$, the objective function value is lower than the existing system by $\$ 775,146$ and it could be observed that there exist 47 direct routes from 20 different non-hub source points to 15 different non-hub destination points.

In the model proposed by Marin [16], the flows must use hub. When the problem addressed here is solved using the model of Marin, the objective function is calculated as $\$ 2,005,964$. In the proposed model, relaxing the necessity of using hub provides approximately $\$ 40,990$ (2\%) cost advantage. Based on these results, it could be commented that lower costs can be achieved with a mixed system instead of having to use hub. In figure 4 it is shown the total costs for each "number of airports to be located" of both Marin's and suggested models. It is observed that the solution with 35 airports is the best solution.

In table 3 total costs with every Cost Reduction Factor $(\alpha)$ and Cost Reduction Coefficient $(\delta)$ are shown.

In figure 5 Effect of ' $\alpha$ ' and ' $\delta$ ' on the total costs is shown graphically. As described early; while the values of

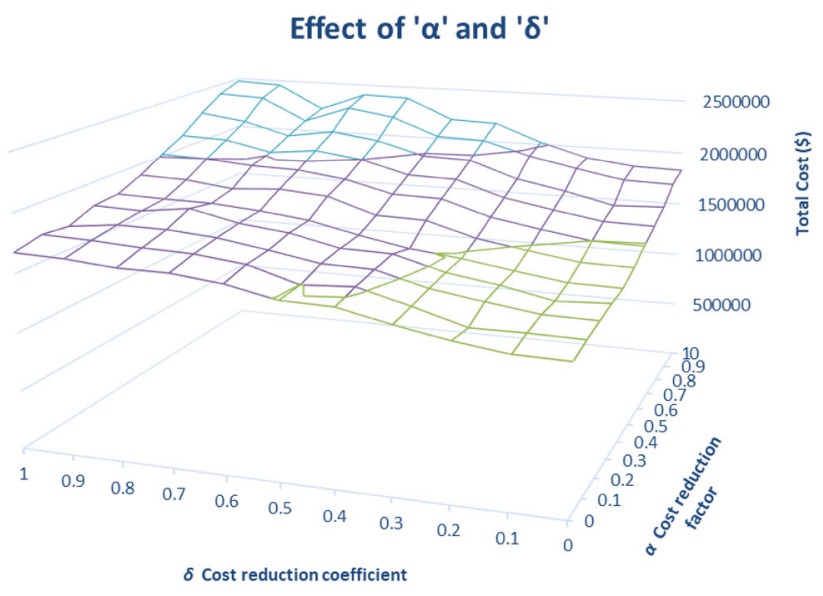

Figure 5. Effect of ' $\alpha$ ' and ' $\delta$ '.

' $\alpha$ ' and ' $\delta$ ' increase, having-to-use-hubs decreases thus total cost increases.

\section{Conclusions}

In this study, it is discussed the real life hub location problem of a public institution in Turkey that should periodically transport a part of its employees between certain points. When the studies in the literature are examined, no study has been encountered that can reflect the basic characteristics of the problem. The common feature of the hub location problems in the literature is that the route is banned without using a hub between the nodes and that all nodes in the network are hub candidates. However, since some nodes do not have sufficient infrastructure, they cannot become hub candidates and direct flows for some nodes create a lower cost in the addressed problem.

In this study, in accordance with the structure of the problem discussed, a new dimension has been added to the hub location problems in the literature. Firstly, obligation to use of hubs for the flows between origin-destination pairs is relaxed. Secondly, nodes with insufficient infrastructure are 
prevented from being assigned as hubs. Lastly, hubs' capacities are made to be affected by the flow not only from hubs but also spokes.

The results showed that the proposed model produced a lower total cost compared to the studies in the literature. Proposed model, when compared to the current system, provides a cost advantage of $\$ 790,755$ (40\%) and when compared to the Marin's [16] model, which does not allow direct flow between non-hub nodes, provides a cost advantage of $\$ 40,990(2 \%)$. Based on the obtained data, it is evaluated that the hybrid model which is developed in this work and permits the direct flow could produce more economical results than allowing only hub-to hub-flow model.

As a further study it can be proposed to include road transportation from hub to spoke into the mathematical model. This distribution can be handled as a vehicle routing problem. We think that by this way the objective function value will be decreased furthermore.

\section{References}

[1] Alumur S and Kara B Y 2008 Network hub location problems: The state of the art. European Journal of Operational Research 190(1): 1-21

[2] O'kelly M E 1986 The Location of Interacting Hub Facilities. Transportation Science 20(2): 92-106

[3] O'kelly M E 1987 A Quadratic Integer Program for the Location of Interacting Hub Facilities. European Journal of Operational Research 32(3): 393-404

[4] O'kelly M E 1994 Hub Facility Location with Fixed Costs. Papers in Regional Science 713: 293-306

[5] Campbell J F 1994 Integer programming formulations of discrete hub location problems. European Journal of Operational Research 72: 387-405

[6] Campbell J F 1996, Hub Location and the P-Hub Median Problem. Operations Research 44(6): 923-935

[7] Aykin T 1990 On a Quadratic Integer Program for the Location of Interacting Hub Facilities. European Journal of Operational Research 46(3): 409-411

[8] Aykin T 1994 Lagrangean Relaxation Based Approaches to Capacitated Hub-and-Spoke Network Design Problem. European Journal of Operational Research 79(3): 501-523

[9] Aykin T 1995a Networking Policies for Hub-and-Spoke Systems with Application to the Air Transportation System. Transportation Science 29(3): 201-221

[10] Aykin T 1995b The Hub Location and Routing Problem. European Journal of Operational Research 83: 200-219

[11] Klincewicz J G 1991 Heuristics for the P-Hub Location Problem. European Journal of Operational Research 53(1): 25-37

[12] Klincewicz J G 1992 Avoiding Local Optima in Thep-Hub Location Problem Using Tabu Search and GRASP. Annals of Operations Research 40(1): 283-302

[13] Ebery J, Krishnamoorthy M, Ernst A and Boland N 2000 The capacitated multiple allocation hub location problem: Formulations and algorithms. European Journal of Operational Research 120(3): 614-631
[14] Sasaki M and Fukushima M 2003 On the hub-and-spoke model with arc capacity constraints. Journal of the Operations Research Society of Japan 46(4): 409-428

[15] Boland N, Krishnamoorthy M, Ernst A T and Ebery J 2004 Preprocessing and cutting for multiple allocation hub location problems. European Journal of Operational Research 155(3): 638-653

[16] Marín A 2005 Formulating and solving splittable capacitated multiple allocation hub location problems. Computers and Operations Research 32(12): 3093-3109

[17] Rodriguez V, Alvarez M J and Barcos L 2007 Hub location under capacity constraints. Transportation Research Part E: Logistics and Transportation Review 43(5): 495-505

[18] Rodriguez-Martin I and Salazar-Gonzalez J J 2008 Solving a capacitated hub location problem. European Journal of Operational Research 184(2): 468-479

[19] Gelareh S and Pisinger D 2011 Fleet deployment, network design and hub location of liner shipping companies. Transportation Research Part E: Logistics and Transportation Review 47: 947-964

[20] Sender J and Clausen U 2013 Heuristics for Solving a Capacitated Multiple Allocation Hub Location Problem with Application in German Wagonload Traffic. Electronic Notes in Discrete Mathematics 41: 13-20

[21] Shahabi M and Unnikrishnan A 2014 Robust hub network design problem. Transportation Research Part E: Logistics and Transportation Review 70: 356-373

[22] Karimi H and Setak M 2014 Proprietor and customer costs in the incomplete hub location-routing network topology. Applied Mathematical Modelling 38(3): 1011-1023

[23] Fang C, Shu-Xia L and Yi-Fan W 2016 Multiple allocation hub location problem with flow-dependent set-up cost, Qi E. (eds.) In: Proceedings of the 6th International Asia Conference on Industrial Engineering and Management Innovation Atlantis Press, Paris

[24] Wang Y and Huang Y 2015 Incremental Optimization of Hub and Spoke Network for the Spokes' Numbers and Flow. Mathematical Problems in Engineering 1-12

[25] Serper E Z and Alumur S A 2016 The design of capacitated intermodal hub networks with different vehicle types. Transportation Research Part B: Methodological 86: 51-65

[26] Mokhtar H, Redi A A N P, Krishnamoorthy M and Ernst A T 2019 An intermodal hub location problem for container distribution in Indonesia. Computers and Operations Research 104: 415-432

[27] Kartal Z, Hasgul S and Ernst A T 2017 Single allocation p-hub median location and routing problem with simultaneous pick-up and delivery. Transportation Research Part E: Logistics and Transportation Review 108: 141-159

[28] Karimi B, Bashiri M and Nikzad E 2018 Multi-commodity Multimodal Splittable Logistics Hub Location Problem with Stochastic Demands. International Journal of Engineering 31(11): 1935-1942

[29] Mohammadi M, Jula P and Tavakkoli-Moghaddam R 2019 Reliable single-allocation hub location problem with disruptions. Transportation Research Part E: Logistics and Transportation Review 123: 90-120

[30] Zhalechian M, Torabi S and Mohammadi M 2018 Hub-andspoke network design under operational and disruption risks. Transportation Research Part E: Logistics and Transportation Review 109: 20-43 
[31] Hu L, Zhu J X, Wang Y and Lee L H 2018 Joint design of fleet size, hub locations, and hub capacities for third-party logistics networks with road congestion constraints. Transportation Research Part E: Logistics and Transportation Review 118: 568-588

[32] Aygün S, Kose E and Aplak H S 2015 Capacitated multiple allocation hub location problem which allows direct flow between nodes. Journal of the Faculty of Engineering and Architecture of Gazi University 30(4): 649-658
[33] O'kelly M E and Miller H J 1994 The hub network design problem: a review and synthesis. Journal of Transport Geography 2(1): 31-40

[34] Mayer G and Wagner B 2002 HubLocator: an exact solution method for the multiple allocation hub location problem. Computers and Operations Research 29(6): 715-739

[35] Turkish Statistical Institute, www.turkstat.gov.tr (accessed 15 February 2018)

[36] General Directorate of Highways, www.kgm.gov.tr/Sayfalar/ KGM/SiteTr/Root/Uzakliklar.aspx. (accessed 15 February 2018) 